\title{
Association between Smoking and Health Outcomes in Postmenopausal Women Living with Multiple Sclerosis
}

\author{
Rachel Jawahar, ${ }^{1}$ Unsong $\mathbf{O h},{ }^{2}$ Charles Eaton, ${ }^{3}$ \\ Nicole Wright, ${ }^{4}$ Hilary Tindle, ${ }^{5}$ and Kate L. Lapane ${ }^{6}$ \\ ${ }^{1}$ Department of Epidemiology and Community Health, Virginia Commonwealth University School, Richmond, \\ VA 23284, USA \\ ${ }^{2}$ Department of Neurology, Virginia Commonwealth University School, Richmond, VA 23284, USA \\ ${ }^{3}$ Center for Primary Care and Prevention, Memorial Hospital of Rhode Island, Pawtucket, RI 02861, USA \\ ${ }^{4}$ Department of Epidemiology, University of Alabama Birmingham, Birmingham, AL 35294, USA \\ ${ }^{5}$ Department of Medicine, University of Pittsburgh, Pittsburgh, PA 15260, USA \\ ${ }^{6}$ Department of Quantitative Health Sciences, University of Massachusetts Medical School, \\ 55 Lake Avenue North, Worcester, MA 01655, USA
}

Correspondence should be addressed to Kate L. Lapane; kate.lapane@umassmed.edu

Received 7 December 2013; Revised 10 March 2014; Accepted 19 March 2014; Published 22 April 2014

Academic Editor: S. Jacobson

Copyright (c) 2014 Rachel Jawahar et al. This is an open access article distributed under the Creative Commons Attribution License, which permits unrestricted use, distribution, and reproduction in any medium, provided the original work is properly cited.

\begin{abstract}
Background. In multiple sclerosis (MS), symptom management and improved health-related quality of life (HrQOL) may be modified by smoking. Objective. To evaluate the extent to which smoking is associated with worsened health outcomes and HrQOL for postmenopausal women with MS. Methods. We identified 251 Women's Health Initiative Observational Study participants with a self-reported MS diagnosis. Using a linear model, we estimated changes from baseline to 3 years for activities of daily living, total metabolic equivalent tasks (MET) hours per week, mental and physical component scales (MCS, PCS) of the SF-36, and menopausal symptoms adjusting for years since menopause and other confounders. Results. Nine percent were current and $50 \%$ past smokers. Age at smoking initiation was associated with significant changes in MCS during menopause. PCS scores were unchanged. While women who had ever smoked experienced an increase in physical activity during menopause, the physical activity levels of women who never smoked declined. Residual confounding may explain this finding. Smoking was not associated with change in menopausal symptoms during the 3-year follow-up. Conclusion. Smoking was not associated with health outcomes among postmenopausal women with MS.
\end{abstract}

\section{Introduction}

Multiple sclerosis (MS) is a chronic disease of the central nervous system with symptoms that impact healthrelated quality of life (HrQOL) $[1,2]$. MS disproportionately affects more women than men [3]. The extent to which the menopausal transition in women worsens MS symptoms remains largely unexplored. Previous studies have addressed symptom management in MS through modifiable risk factors such as smoking [4]. Forty percent [5, 6] of women with MS are current smokers, yet how smoking affects MS outcomes after menopause is unknown.
In both menopausal and postmenopausal women, current smokers report increased odds of vasomotor symptoms, hot flashes, forgetfulness [7], and worsened HrQOL [8]. In MS, smoking has been linked to increased incidence [6] and faster MS progression [5,9] leading to worse health outcomes [10]. More than 37 million women are approaching or experiencing menopause [11] in the aging U.S. population [12]. This underscores the need for greater focus on symptom management for women with MS during the menopausal transition and beyond. Using a multicenter prospective study of U.S. postmenopausal women, we aimed to evaluate the extent to which health outcomes including health-related 
quality of life and indicators of physical functioning are worsened for women with MS who currently smoke or previously smoked relative to women with MS who never smoked.

\section{Materials and Methods}

The Virginia Commonwealth University Institutional Review Board approved this study.

2.1. Participants. The Women's Health Initiative Observational Study (WHI-OS), sponsored by the National Institutes of Health and the National Heart, Lung, and Blood Institute, followed 93,676 racially diverse women aged 50 to 79 years and recruited from 40 clinical centers throughout the U.S. [13]. Women were eligible for participation in the WHI-OS if they were postmenopausal, not enrolled in other WHI clinical trials, and unlikely to relocate or die within 3 years. Protocols for WHI-OS were reviewed and approved by human subjects review committees at participating institutions [14]. Participants for the current study were included if they reported "yes" to the question "Has a doctor ever told you you had MS?" Analyses included 251 WHI-OS participants who completed baseline and year three assessments and had complete information on smoking history.

2.2. Determination of Smoking Status. Smoking status was determined at baseline using the following questions: "During your entire life, have you smoked at least 100 cigarettes?" and "Do you smoke cigarettes now?" The responses to these questions were combined to classify women as current, past, or never smokers. For women who reported ever having smoked, we classified women according to their age at smoking initiation ( $<20$ years, $20-24$ years, and $\geq 25$ years), the number of cigarettes smoked per day ( $<15 /$ day, $\geq 15 /$ day), and the number of years smoked regularly ( $<30, \geq 30$ years). Past smokers were asked age at cessation and classified as $<40$ years, $\geq 40$ years. Calculated by the WHI Clinical Coordinating Center, the number of smoking pack-years [15] was categorized as $<10,10-29$, and $\geq 30$ pack-years.

2.3. Outcome Ascertainment. We evaluated HrQOL, menopausal symptoms, and indicators of physical functioning and activity measures. HrQOL was measured using the RAND 36-item health survey (SF-36) [16] which has been validated in MS patients [17]. We calculated the mental component score (MCS) and the physical component score (PCS), each ranging from 0 (lower health) to 100 points (better health) with 50 representing the mean score in the general population. Activities of daily living (ADLs) (modified from the original Katz et al. [18] index) consisted of four separate items regarding ability to eat, ability to get in and out of bed, dress, and/or take a bath on her own. Each item had three possible values $(1=$ without help, 2 = some help, and 3 = completely unable). For baseline and year 3, scores (ranging from 4 to 12) were summed to represent overall ADLs with a lower score indicating better health. Baseline ADL scores were subtracted from year $3 \mathrm{ADL}$ scores so that a positive change score represented a decline in ADLs. Physical activity was computed from self-reported energy expenditures for recreational activities, including walking and other mild/moderate/strenuous activities (total metabolic equivalent tasks (MET) hours/week). Calculated MET hours per week are comparable to physical activity diaries [19]. Baseline scores were subtracted from year 3 scores such that a positive change score indicated an increase in physical activity.

Our focus was on menopausal symptoms, rather than neurological symptoms. Based on the Postmenopausal Estrogen/Progestin Interventions symptom tool [20], we considered the following items as menopausal symptoms: forgetfulness, difficulty in concentrating, mood swings, joint pain or stiffness, headaches or migraines, breast tenderness, increased or decreased appetite, hot flashes, night sweats, vaginal/genital irritation, and vaginal/genital dryness. Participants were asked how bothersome each symptom was in the past four weeks $(0=$ did not occur, $1=$ mild, $2=$ moderate, and 3 = severe). For each symptom, we created a binary variable coded as $0=$ did not occur and $1=$ symptom occurred (mild, moderate, and severe). At baseline and year 3, a summary measure was constructed by adding the number of symptoms reported (minimum score possible: 0 ; maximum score possible: 12 ). We treated the outcome as a continuous variable by subtracting the baseline sum from year 3 summary measure.

2.4. Potential Confounders. Potential confounders considered included age, education, race/ethnicity, years since menopause, alcohol use, body mass index (BMI), depression, menopausal hormone therapy (MHT) use, and vitamin D intake. Years since menopause were calculated as the difference between the youngest reported age when menses ceased (age when participant experienced last menstruation, oophorectomy, or initiated MHT) and age at baseline. Baseline alcohol use was assessed using the Food Frequency Questionnaire (FFQ) and categorized as never, past, and current use. BMI was calculated in $\mathrm{kg} / \mathrm{m}^{2}$ units from heights and weights measured with calibrated balances and stadiometers $\left(<18.5 \mathrm{~kg} / \mathrm{m}^{2}, 18.5 \mathrm{~kg} / \mathrm{m}^{2}\right.$, and $<25 \mathrm{~kg} / \mathrm{m}^{2}$; $25 \mathrm{~kg} / \mathrm{m}^{2}$ to $30 \mathrm{~kg} / \mathrm{m}^{2}$; and $\geq 30 \mathrm{~kg} / \mathrm{m}^{2}$ ). MHT (unopposed estrogen and/or estrogen plus progesterone) was classified as current, past, or never use. Using FFQ and supplement use, vitamin D insufficiency was defined as <400 IU [21], as this was the standard used at the time of the study. The CES-D [22] was used to evaluate the depression status and participants with scores above 16 were considered to have clinical levels of depression.

2.5. Statistical Analysis. We reported the sociodemographic, clinical, and smoking characteristics by smoking status. Multivariable linear models estimated associations between differences in 3-year HrQOL, ADL, and physical activity scores and number of menopausal symptoms by baseline smoking status. We examined univariate distributions of each score's differences and years since menopause to ensure normality. Multicollinearity was ruled out by evaluating 
correlations between each potential confounder. We visually inspected residual plots, Q-Q plots, and studentized residuals. Beta coefficients and corresponding 95\% confidence intervals (CI) were derived from the adjusted models and corrected for the number of outcomes evaluated in the study using Bonferroni's method.

\section{Results}

Of the 251 women with MS, $6 \%$ changed smoking status from baseline measures to year 3. Nearly $9 \%$ of women were current smokers $(n=23)$ and $50.2 \%$ were past smokers $(n=126)$ (Table 1). Current smokers were younger than past smokers. While $64.7 \%$ of never smokers reported ever using alcohol, $82.6 \%$ of current and $80.2 \%$ of past smokers reported current alcohol use. Depression varied by smoking status with $9.1 \%$ of current smokers, $20.8 \%$ of former smokers, and $25.0 \%$ of those who never smoked experiencing depression at baseline. All women, regardless of smoking status, had less than 800 IU vitamin D intake per day from food, over the counter supplements, and/or prescribed supplements. There were no current smokers who had less than 400 IU vitamin D; $3.2 \%$ and $4.9 \%$ of past and never smokers, respectively, had levels below this threshold. Most women began smoking at 25 years of age or older and most reported regularly smoking less than 15 cigarettes per day (Table 1).

Table 2 shows the changes in HrQOL from baseline to year three of follow-up by smoking status. Age at smoking initiation was associated with significant changes in MCS during menopause in women with MS. PCS scores were unchanged. No differences in change in MCS scores were observed based on overall smoking status (current versus past versus never smoker). Smoking pack-years were not associated with changes in PCS or MCS. Past smokers who reported quitting at the age of 40 or older had lower MCS scores (adjusted $\beta$ : $-5.21,95 \%$ CI: -9.3 to -1.1 ).

Table 3 shows the association between various definitions of smoking and change in ADLs and physical activity from baseline to year 3. None of the associations between ADL change and smoking were statistically significant. Having ever smoked was associated with changes in physical activity. While all women's physical activity declined, current and former smokers were less likely to have reported reductions in their physical activity relative to nonsmokers. For example, women who reported never smoking experienced a decrease of 3.66 MET task hours per week in physical activity. Former smokers experienced a decline of 0.60 MET task hours and current smokers a decline of 0.19 MET task hours. Relative to women who never smoked, we observed a slower decline in physical activity for former smokers (adjusted $\beta: 3.76,95 \%$ CI: 0.00 to 7.6 ).

The five most prevalent menopausal symptoms reported at baseline included joint pain/stiffness (74\%), forgetfulness (68\%), difficulty in concentrating (48\%), headaches (45\%), mood swings (42\%), and vaginal dryness (31\%). Aside from joint pain (10\%), few ranked symptoms as severe. Differences in change in menopausal symptoms by overall smoking status were not observed (Table 4). Changes in menopausal symptoms were minimal over the 3 -year period. None of the variables categorizing smoking status were associated with changes in menopausal symptoms.

\section{Conclusions}

To our knowledge, this is the first study to estimate the association between smoking status and outcomes in postmenopausal women with MS. Although the WHI-OS followed nearly 100,000 women, only a few hundred women noted that a physician had told them they had MS. Nearly half of these women were past smokers, and most had ceased at the age of 40 or older. Women with MS who began smoking at a young age had worse mental HrQOL at year 3 than at baseline, indicating a decline in cognition during menopause for those who began smoking at the age of 20 or younger. Little change was observed in ADLs regardless of smoking status. While never smokers reported a reduction in physical activity from baseline to year 3 , the reductions in physical activity reported by current and former smokers were less marked. The study included all postmenopausal women even though most women experience menopausal symptoms between the ages of 50 to 59 . This may explain why we did not observe significant changes in reports of menopausal symptoms within the 3-year observation period. Nevertheless, smoking status was not associated with changes in menopausal symptoms.

Estimates of prevalence of smoking are much lower in this study than in previous reports of $40 \%$ [5]. We found that only $9 \%$ of women reported current smoking and 59\% reported that they had ever smoked. Our data are consistent with previous findings reporting $6.3 \%$ current smokers in the WHI-OS [23]. The findings more likely reflect the strong decline in smoking prevalence observed in both men and women [24]. Previous studies have linked smoking history to worse outcomes in the MS disease process [5]. Thus, the possibility of survival bias must be considered when interpreting these findings. Changes in HrQOL and physical functioning and activity measures may be more strongly related to current smoking than past smoking. These data must be considered in light of the unique sample. Decreases in motor function have been noted for MS patients within 10 minutes of smoking a cigarette [25]. Current smokers were less likely to engage in more intense physical activity over eight years of follow-up [26]. The patterns of changes in physical activity by smoking status may suggest that current smokers compensate for smoking by maintaining physical activity. This finding must be confirmed in studies with a larger sample size. It is also possible that this association is confounded by markers of disease severity in MS or residual confounding by comorbid conditions. Lastly, survival bias cannot be ruled out.

Smoking has been associated with increases in MS incidence through its alterations to the blood-brain barrier [27] by nitric oxide [28]. Younger age at smoking initiation has been shown to be associated with an increased risk of MS [29] and worsened prognosis from disease onset [30]. In our study, younger age at smoking initiation was associated with decrease in mental HrQOL. Because women who reported 
TABLE 1: Baseline characteristics of postmenopausal women with multiple sclerosis by smoking status in the Women's Health Initiative Observational Study.

\begin{tabular}{|c|c|c|c|}
\hline Baseline characteristics & Current smoker $(n=23)$ & Past smoker $(n=126)$ & Never smoker $(n=102)$ \\
\hline & & Iedian (standard deviation) & \\
\hline \multirow[t]{2}{*}{ Years since menopause } & $11.9(7.2)$ & $13.2(8.4)$ & $13.8(9.4)$ \\
\hline & & Percentages & \\
\hline \multicolumn{4}{|l|}{ Age } \\
\hline$<50-59$ years & 65.2 & 48.4 & 46.1 \\
\hline $60-69$ years & 34.8 & 40.5 & 37.3 \\
\hline $70-79+$ years & 0 & 11.1 & 16.7 \\
\hline \multicolumn{4}{|l|}{ Race/ethnicity } \\
\hline Non-Hispanic white & 89.5 & 90.0 & 90.5 \\
\hline Non-Hispanic black & 10.5 & 6.4 & 2.4 \\
\hline Hispanic & 0 & 3.6 & 3.6 \\
\hline \multicolumn{4}{|l|}{ Education } \\
\hline$\leq$ High school & 13.0 & 16.0 & 16.8 \\
\hline Some college & 47.8 & 36.0 & 36.6 \\
\hline$\geq$ College graduate & 39.1 & 48.0 & 46.5 \\
\hline Have any health insurance & 100 & 98.4 & 95.1 \\
\hline Depressed & 9.1 & 20.8 & 25.0 \\
\hline \multicolumn{4}{|l|}{ Body mass index $\left(\mathrm{kg} / \mathrm{m}^{2}\right)$} \\
\hline$<18.5$ (underweight) & 8.7 & 4.8 & 7.8 \\
\hline 18.5 to $<25$ (normal) & 47.8 & 48.4 & 42.2 \\
\hline 25 to $<30$ (overweight) & 26.1 & 26.2 & 33.3 \\
\hline $30+($ obese $)$ & 17.4 & 20.6 & 16.7 \\
\hline \multicolumn{4}{|l|}{ Alcohol use } \\
\hline Never drinker & 0 & 4.0 & 18.6 \\
\hline Past drinker & 17.4 & 15.9 & 16.7 \\
\hline Current drinker & 82.6 & 80.2 & 64.7 \\
\hline \multicolumn{4}{|l|}{ Menopause hormone therapy } \\
\hline Never user & 34.8 & 34.1 & 35.3 \\
\hline Past user & 8.7 & 18.3 & 12.8 \\
\hline Current user & 56.5 & 47.6 & 52.0 \\
\hline Vitamin $\mathrm{D}<400$ IU per day & 0 & 3.2 & 4.9 \\
\hline \multicolumn{4}{|l|}{ Age started smoking (years) } \\
\hline$<20$ & 16.1 & 12.0 & N/A \\
\hline 20 to 24 & 30.1 & 31.0 & N/A \\
\hline 25 or older & 53.8 & 57.1 & N/A \\
\hline \multicolumn{4}{|l|}{ Cigarettes smoked (per day) } \\
\hline$<15$ & 52.0 & 55.1 & N/A \\
\hline 15 or more & 48.0 & 44.9 & N/A \\
\hline \multicolumn{4}{|l|}{ Years smoked regularly } \\
\hline$<10$ & 4.3 & 27.3 & N/A \\
\hline 10 to 29 & 20.2 & 47.6 & N/A \\
\hline 30 to 49 & 63.4 & 23.7 & N/A \\
\hline 50 and more & 12.0 & 1.4 & N/A \\
\hline \multicolumn{4}{|l|}{ Pack-years } \\
\hline$<10$ & 22.2 & 44.9 & N/A \\
\hline 10 to 29 & 35.1 & 31.7 & N/A \\
\hline 30 to 49 & 29.2 & 14.5 & N/A \\
\hline 50 or more & 13.6 & 8.9 & N/A \\
\hline \multicolumn{4}{|l|}{ Age quit smoking (years) } \\
\hline$<20$ & $\mathrm{~N} / \mathrm{A}$ & 1.8 & $\mathrm{~N} / \mathrm{A}$ \\
\hline 20 to 29 & N/A & 19.2 & N/A \\
\hline 30 to 39 & N/A & 25.2 & N/A \\
\hline 40 or older & N/A & 53.8 & N/A \\
\hline
\end{tabular}


TABLE 2: Association between smoking status and change in health-related quality of life measures over 3 years among postmenopausal women with multiple sclerosis in the Women's Health Initiative Observational Study.

\begin{tabular}{|c|c|c|c|c|c|c|}
\hline \multirow{3}{*}{ Exposure } & \multicolumn{3}{|c|}{$\Delta$ Physical component score (3-year baseline) } & \multicolumn{3}{|c|}{$\Delta$ Mental component score (3-year baseline) } \\
\hline & \multirow{2}{*}{$\begin{array}{l}\text { Mean change } \\
\text { (standard } \\
\text { deviation) }\end{array}$} & \multicolumn{2}{|c|}{$\beta$-Coefficient } & \multirow{2}{*}{$\begin{array}{l}\text { Mean change } \\
\text { (standard } \\
\text { deviation) }\end{array}$} & \multicolumn{2}{|c|}{$\beta$-Coefficient } \\
\hline & & Crude & $\begin{array}{c}\text { Adjusted }^{1} \\
\text { (95\% confidence } \\
\text { interval) }\end{array}$ & & Crude & $\begin{array}{c}\text { Adjusted }^{1} \\
\text { (95\% confidence } \\
\text { interval) }\end{array}$ \\
\hline \multicolumn{7}{|l|}{ Smoking history } \\
\hline Never smokers & $-0.65(8.6)$ & Ref. & Ref & $-0.84(12.1)$ & Ref. & Ref. \\
\hline Ever smokers & $-1.10(9.5)$ & -0.45 & $\begin{array}{c}0.05 \\
(-3.3 \text { to } 3.4)\end{array}$ & $0.12(11.5)$ & 0.96 & $\begin{array}{c}0.25 \\
(-4.1 \text { to } 4.6)\end{array}$ \\
\hline Former smokers & $-0.74(9.1)$ & -0.10 & $\begin{array}{c}1.67 \\
(-4.0 \text { to } 7.3)\end{array}$ & $-0.25(11.2)$ & 0.59 & $\begin{array}{c}-1.82 \\
(-5.9 \text { to } 9.5)\end{array}$ \\
\hline Current smokers & $-2.97(11.7)$ & -2.33 & $\begin{array}{c}-0.90 \\
(-6.7 \text { to } 4.9)\end{array}$ & $2.08(13.4)$ & 2.91 & $\begin{array}{c}1.80 \\
(-9.3 \text { to } 5.6)\end{array}$ \\
\hline \multicolumn{7}{|l|}{$\begin{array}{l}\text { Age started smoking } \\
\text { (years) }\end{array}$} \\
\hline$<20$ & $-1.25(9.6)$ & 1.25 & $\begin{array}{c}1.64 \\
(-7.0 \text { to } 10.3)\end{array}$ & $-0.93(11.4)$ & -10.03 & $\begin{array}{c}-10.45 \\
(-19.1 \text { to }-1.8)\end{array}$ \\
\hline 20 to 24 & $-0.58(9.0)$ & 1.93 & $\begin{array}{c}2.33 \\
(-6.9 \text { to } 11.6)\end{array}$ & $0.72(11.2)$ & -8.37 & $\begin{array}{c}-8.9 \\
(-18.2 \text { to } 0.3)\end{array}$ \\
\hline 25 or older & $-2.51(12.3)$ & Ref. & Ref. & $9.09(12.4)$ & Ref. & Ref. \\
\hline \multicolumn{7}{|c|}{$\begin{array}{l}\text { Cigarettes smoked (per } \\
\text { day) }\end{array}$} \\
\hline$<15$ & $-1.73(8.3)$ & Ref. & Ref. & $0.71(10.3)$ & Ref. & Ref. \\
\hline 15 or more & $-0.46(10.7)$ & 1.64 & $\begin{array}{c}1.32 \\
(-2.9 \text { to } 5.5)\end{array}$ & $-0.47(12.7)$ & -1.07 & $\begin{array}{c}-1.16 \\
(-6.7 \text { to } 4.4)\end{array}$ \\
\hline \multicolumn{7}{|c|}{ Years smoked regularly } \\
\hline$<30$ & $-1.89(8.8)$ & Ref. & Ref. & $1.12(10.6)$ & Ref. & Ref. \\
\hline 30 or more & $-0.12(11.1)$ & 1.77 & $\begin{array}{c}2.41 \\
(-2.0 \text { to } 6.8)\end{array}$ & $-1.89(13.3)$ & -3.01 & $\begin{array}{c}-3.29 \\
(-9.1 \text { to } 2.6)\end{array}$ \\
\hline \multicolumn{7}{|l|}{$\begin{array}{l}\text { Number of smoking } \\
\text { pack-years }\end{array}$} \\
\hline$<10$ & $-1.65(8.2)$ & Ref. & Ref. & $-0.05(11.2)$ & Ref. & Ref. \\
\hline 10 to 29 & $-2.31(9.0)$ & -0.14 & $\begin{array}{c}-1.55 \\
(-6.0 \text { to } 2.9)\end{array}$ & $2.89(10.1)$ & 3.19 & $\begin{array}{c}3.85 \\
(-2.0 \text { to } 9.7)\end{array}$ \\
\hline 30 or more & $1.21(9.9)$ & 3.10 & $\begin{array}{c}2.41 \\
(-4.5 \text { to } 9.3)\end{array}$ & $-4.15(13.9)$ & -2.48 & $\begin{array}{c}-3.49 \\
(-12.5 \text { to } 5.5)\end{array}$ \\
\hline \multicolumn{7}{|c|}{ Age quit smoking (years) } \\
\hline$<40$ & $-2.94(8.9)$ & Ref. & Ref. & $1.79(10.8)$ & Ref. & Ref. \\
\hline 40 or older & $0.46(9.9)$ & 2.62 & $\begin{array}{c}3.46 \\
(-1.3 \text { to } 8.2) \\
\end{array}$ & $-2.82(11.9)$ & -4.94 & $\begin{array}{c}-4.44 \\
(-10.8 \text { to } 1.9) \\
\end{array}$ \\
\hline
\end{tabular}

${ }^{1}$ Adjusted for the following baseline confounders: age, education, race/ethnicity, years since menopause, alcohol use, depression, and body mass index. Bonferroni corrections applied to confidence intervals to adjust for multiple comparisons.

ever having smoked may be more likely to develop progressive disease than never smokers [5], smoking cessation at older ages may be too late to improve mental HrQOL in postmenopause. Regardless of our specific findings, counseling women with MS to quit smoking at the earliest age possible is prudent.
The strengths of this study include the diverse outcomes available in the WHI-OS. While no MS-specific measures were collected, many of the outcomes measured (e.g., SF-36 scales, ADLs) are included in MS-specific composite measures. The WHI-OS provides data not always present in MS registries, such as specific questions regarding menopausal 
TABLE 3: Association between smoking status and change in physical functioning and activity scores over 3 years among postmenopausal women with multiple sclerosis in the Women's Health Initiative Observational Study.

\begin{tabular}{|c|c|c|c|c|c|c|}
\hline \multirow{3}{*}{ Exposure } & \multicolumn{3}{|c|}{$\Delta$ Activities of daily living (3-year baseline) } & \multicolumn{3}{|c|}{$\Delta$ Physical activity (3-year baseline) } \\
\hline & \multirow{2}{*}{$\begin{array}{l}\text { Mean change } \\
\text { (standard } \\
\text { deviation) }\end{array}$} & \multicolumn{2}{|c|}{$\beta$-Coefficient } & \multirow{2}{*}{$\begin{array}{l}\text { Mean change } \\
\text { (standard } \\
\text { deviation) }\end{array}$} & \multicolumn{2}{|c|}{$\beta$-Coefficient } \\
\hline & & Crude & $\begin{array}{c}\text { Adjusted }^{1} \\
\text { (95\% confidence } \\
\text { interval) }\end{array}$ & & Crude & $\begin{array}{c}\text { Adjusted }^{1} \\
\text { (95\% confidence } \\
\text { interval) }\end{array}$ \\
\hline \multicolumn{7}{|l|}{ Smoking history } \\
\hline Never smokers & $0.01(0.5)$ & Ref. & Ref. & $-3.66(12.3)$ & Ref. & Ref. \\
\hline Ever smokers & $-0.02(0.6)$ & -0.03 & $\begin{array}{c}-0.06 \\
(-0.3 \text { to } 0.1)\end{array}$ & $-0.53(9.8)$ & 3.35 & $\begin{array}{c}3.81 \\
(0.00 \text { to } 7.6)\end{array}$ \\
\hline Former smokers & $-0.01(0.53)$ & 0.09 & $\begin{array}{c}0.09 \\
(-0.2 \text { to } 0.4)\end{array}$ & $-0.60(10.2)$ & -0.76 & $\begin{array}{c}-1.06 \\
(-7.9 \text { to } 5.7)\end{array}$ \\
\hline Current smokers & $-0.10(0.62)$ & -0.11 & $\begin{array}{c}-0.14 \\
(-0.5 \text { to } 0.2)\end{array}$ & $-0.19(7.0)$ & 4.00 & $\begin{array}{c}4.72 \\
(-2.3 \text { to } 11.7)\end{array}$ \\
\hline \multicolumn{7}{|l|}{$\begin{array}{l}\text { Age started smoking } \\
\text { (years) }\end{array}$} \\
\hline$<20$ & $0.0(0.6)$ & 0.25 & $\begin{array}{c}0.25 \\
(-0.3 \text { to } 0.8)\end{array}$ & $-0.52(9.3)$ & -1.45 & $\begin{array}{c}-1.09 \\
(-11.6 \text { to } 9.4)\end{array}$ \\
\hline 20 to 24 & $-0.03(0.4)$ & 0.22 & $\begin{array}{c}0.21 \\
(-0.3 \text { to } 0.8)\end{array}$ & $-0.89(11.3)$ & -2.06 & $\begin{array}{c}-2.02 \\
(-13.2 \text { to } 9.4)\end{array}$ \\
\hline 25 or older & $0.25(0.5)$ & Ref. & Ref. & $9.09(12.4)$ & Ref. & Ref. \\
\hline \multicolumn{7}{|c|}{$\begin{array}{l}\text { Cigarettes smoked (per } \\
\text { day) }\end{array}$} \\
\hline$<15$ & $-0.04(0.39)$ & Ref. & Ref. & $0.14(11.0)$ & Ref. & Ref. \\
\hline 15 or more & $0.0(0.7)$ & 0.04 & $\begin{array}{c}0.05 \\
(-0.2 \text { to } 0.3)\end{array}$ & $-1.2(8.4)$ & -1.80 & $\begin{array}{c}-1.58 \\
(-6.4 \text { to } 3.3)\end{array}$ \\
\hline \multicolumn{7}{|c|}{ Years smoked regularly } \\
\hline$<30$ & $-0.08(0.6)$ & Ref. & Ref. & $0.04(11.1)$ & Ref. & Ref. \\
\hline 30 or more & $0.06(0.5)$ & 0.14 & $\begin{array}{c}0.15 \\
(-0.1 \text { to } 0.4)\end{array}$ & $-1.07(6.8)$ & -0.92 & $\begin{array}{c}-0.93 \\
(-6.1 \text { to } 4.2)\end{array}$ \\
\hline \multicolumn{7}{|l|}{$\begin{array}{l}\text { Number of smoking } \\
\text { pack- years }\end{array}$} \\
\hline$<10$ & $-0.06(0.4)$ & Ref. & Ref. & $-0.84(9.6)$ & Ref. & Ref. \\
\hline 10 to 29 & $-0.02(0.3)$ & -0.04 & $\begin{array}{c}-0.05 \\
(-0.3 \text { to } 0.2)\end{array}$ & $-0.96(11.8)$ & 2.18 & $\begin{array}{c}2.50 \\
(-2.7 \text { to } 7.7)\end{array}$ \\
\hline 30 or more & $-0.27(1.2)$ & -0.29 & $\begin{array}{c}-0.28 \\
(-0.7 \text { to } 0.1)\end{array}$ & $-0.40(4.6)$ & 0.83 & $\begin{array}{c}1.76 \\
(-6.3 \text { to } 9.9)\end{array}$ \\
\hline \multicolumn{7}{|c|}{ Age quit smoking (years) } \\
\hline$<40$ & $0.01(0.5)$ & Ref. & Ref. & $-0.60(10.1)$ & Ref. & Ref. \\
\hline 40 or older & $-0.10(0.6)$ & -0.16 & $\begin{array}{c}-0.15 \\
(-0.4 \text { to } 0.1)\end{array}$ & $-1.09(8.8)$ & -0.58 & $\begin{array}{c}-0.67 \\
(-6.2 \text { to } 4.8) \\
\end{array}$ \\
\hline
\end{tabular}

${ }^{1}$ Adjusted for the following baseline confounders: age, education, race/ethnicity, years since menopause, alcohol use, depression, and body mass index. Bonferroni corrections applied to confidence intervals to adjust for multiple comparisons.

symptoms and the severity of the symptoms. Further, the WHI included detailed information on the frequency and duration of smoking (e.g., number of cigarettes per day, years of smoking before cessation) as well as an array of potentially confounding factors such as sociodemographics, BMI, and vitamin $\mathrm{D}$ intake.
Several limitations must be kept in mind. The sample size is small. Some may question the participant-reported physician diagnoses of MS used in the WHI. A validation study of self-reported diagnosis of MS in the North American Research Committee on MS registry showed a 98.79\% sensitivity of self-report when compared to chart review and/or 
TABLE 4: Association between smoking status and change in menopausal symptoms over 3 years among postmenopausal women with multiple sclerosis in the Women's Health Initiative Observational Study.

\begin{tabular}{|c|c|c|c|}
\hline \multirow{3}{*}{ Exposure } & \multicolumn{3}{|c|}{$\Delta$ Menopausal symptoms (3-year baseline) } \\
\hline & \multirow{2}{*}{$\begin{array}{c}\text { Mean change } \\
\text { (standard deviation) }\end{array}$} & \multicolumn{2}{|c|}{$\beta$-Coefficient } \\
\hline & & Crude & $\begin{array}{c}\text { Adjusted }^{1} \\
\text { (95\% confidence } \\
\text { interval) }\end{array}$ \\
\hline \multicolumn{4}{|l|}{ Smoking history } \\
\hline Never smokers & $0.15(1.5)$ & Ref. & Ref. \\
\hline Ever smokers & $0.07(1.3)$ & -0.07 & $\begin{array}{c}-0.06 \\
(-0.5 \text { to } 0.4)\end{array}$ \\
\hline Former smokers & $0.06(1.3)$ & -0.12 & $\begin{array}{c}-0.09 \\
(-0.9 \text { to } 0.7)\end{array}$ \\
\hline Current smokers & $0.17(1.5)$ & 0.03 & $\begin{array}{c}0.01 \\
(-0.8 \text { to } 0.9)\end{array}$ \\
\hline \multicolumn{4}{|c|}{ Age started smoking (years) } \\
\hline$<20$ & $0.08(1.5)$ & 0.37 & $\begin{array}{c}0.55 \\
(-0.8 \text { to } 1.9)\end{array}$ \\
\hline 20 to 24 & $0.00(0.9)$ & 0.25 & $\begin{array}{c}0.37 \\
(-1.1 \text { to } 1.8)\end{array}$ \\
\hline 25 or older & $-0.25(1.4)$ & Ref. & Ref. \\
\hline \multicolumn{4}{|c|}{ Cigarettes smoked (per day) } \\
\hline$<15$ & $0.12(1.1)$ & Ref. & Ref. \\
\hline 15 or more & $0.03(1.6)$ & -0.09 & $\begin{array}{c}-0.09 \\
(-0.7 \text { to } 0.5)\end{array}$ \\
\hline \multicolumn{4}{|c|}{ Years smoked regularly } \\
\hline$<30$ & $0.03(1.2)$ & Ref. & Ref. \\
\hline 30 or more & $0.14(1.6)$ & 0.11 & $\begin{array}{c}0.10 \\
(-0.6 \text { to } 0.7)\end{array}$ \\
\hline \multicolumn{4}{|c|}{ Number of smoking pack-years } \\
\hline$<10$ & $0.09(1.4)$ & Ref. & Ref. \\
\hline 10 to 29 & $0.25(1.2)$ & 0.12 & $\begin{array}{c}0.07 \\
(-0.6 \text { to } 0.7)\end{array}$ \\
\hline 30 or more & $-0.12(1.7)$ & -0.99 & $\begin{array}{c}-0.87 \\
(-1.9 \text { to }-0.1)\end{array}$ \\
\hline \multicolumn{4}{|c|}{ Age quit smoking (years) } \\
\hline$<40$ & $0.12(1.2)$ & Ref. & Ref. \\
\hline 40 or older & $0.03(1.4)$ & 0.05 & $\begin{array}{c}0.02 \\
(-0.7 \text { to } 0.7)\end{array}$ \\
\hline
\end{tabular}

\footnotetext{
${ }^{1}$ Adjusted for the following baseline confounders: age, education, race/ethnicity, years since menopause, alcohol use, depression, and body mass index.
} Bonferroni corrections applied to confidence intervals to adjust for multiple comparisons.

physician report [31]. Thus, we were comfortable with our decision to use the self-reported diagnosis of MS available in the WHI-OS.

This study evaluated the effects of smoking on HrQOL and physical measures in postmenopausal women with MS. Despite the large size of the WHI-OS, we had a relatively small sample of women with MS in our study. As these women were healthier than the general population and few were current smokers, effects were not found for all outcomes by all smoking frequencies or duration. Nevertheless, women with MS should be encouraged to quit smoking at the earliest age possible. Patterns were found pointing to an association between initiation of smoking at younger ages and decline of mental HrQOL during menopause. Longitudinal studies of age at smoking initiation and relevant outcomes for older women with MS are needed.

\section{Conflict of Interests}

The authors have no conflict of interests relevant to this paper to report.

\section{Acknowledgments}

The WHI program is funded by the National Heart, Lung, and Blood Institute, National Institutes of Health, U.S. Department of Health and Human Services, through Contract nos. 1WH22110, 24152, 32100-2, 32105-6, 32108-9, 32111-13, 32115, 
32118-32119, 32122, 42107-26, 42129-32, and 44221. The WHI program is supported by Contracts from the National Heart, Lung, and Blood Institute, NIH. The authors thank the WHI investigators and staff for their dedication and the study participants for making the program possible. A listing of WHI investigators can be found at https://www.whi.org/.

\section{References}

[1] A. Forbes, A. While, and M. Taylor, "What people with multiple sclerosis perceive to be important to meeting their needs," Journal of Advanced Nursing, vol. 58, no. 1, pp. 11-22, 2007.

[2] F. Khan and O. Gray, "Disability management and rehabilitation for persons with multiple sclerosis," Neural Regeneration Research, vol. 5, no. 4, pp. 301-309, 2010.

[3] A. Ascherio and K. Munger, "Epidemiology of multiple sclerosis: from risk factors to prevention," Seminars in Neurology, vol. 28, no. 1, pp. 17-28, 2008.

[4] S. Overs, C. M. Hughes, J. K. Haselkorn, and A. P. Turner, "Modifiable comorbidities and disability in multiple sclerosis," Current Neurology and Neuroscience Reports, vol. 12, no. 5, pp. 610-617, 2012.

[5] M. A. Hernán, S. S. Jick, G. Logroscino, M. J. Olek, A. Ascherio, and H. Jick, "Cigarette smoking and the progression of multiple sclerosis," Brain, vol. 128, no. 6, pp. 1461-1465, 2005.

[6] M. A. Hernán, M. J. Olek, and A. Ascherio, "Cigarette smoking and incidence of multiple sclerosis," American Journal of Epidemiology, vol. 154, no. 1, pp. 69-74, 2001.

[7] E. B. Gold, B. Sternfeld, J. L. Kelsey et al., "Relation of demographic and lifestyle factors to symptoms in a multiracial/ethnic population of women 40-55 years of age," American Journal of Epidemiology, vol. 152, no. 5, pp. 463-473, 2000.

[8] R. Luoto, "Hot flushes and quality of life during menopause," BMC Women's Health, vol. 9, article 13, 2009.

[9] F. di Pauli, M. Reindl, R. Ehling et al., "Smoking is a risk factor for early conversion to clinically definite multiple sclerosis," Multiple Sclerosis, vol. 14, no. 8, pp. 1026-1030, 2008.

[10] F. Pittas, A.-L. Ponsonby, I. A. F. van der Mei et al., "Smoking is associated with progressive disease course and increased progression in clinical disability in a prospective cohort of people with multiple sclerosis," Journal of Neurology, vol. 256, no. 4, pp. 577-585, 2009.

[11] Centers for Disease Control and Prevention, "Women's Reproductive Health: Menopause," 2012, http://www.nlm.nih .gov/medlineplus/menopause.html.

[12] C. Werner, “The Older Population: 2010 Census Briefs," 2011, http://www.census.gov/prod/cen2010/briefs/c2010br-09.pdf.

[13] N. F. Woods, A. Z. LaCroix, S. L. Gray et al., "Frailty: emergence and consequences in women aged 65 and older in the Women's Health Initiative observational study," Journal of the American Geriatrics Society, vol. 53, no. 8, pp. 1321-1330, 2005.

[14] A. P. Reiner, A. K. Aragaki, S. L. Gray et al., "Inflammation and thrombosis biomarkers and incident frailty in postmenopausal women," American Journal of Medicine, vol. 122, no. 10, pp. 947954, 2009.

[15] J. Luo, K. Horn, J. K. Ockene et al., "Interaction between smoking and obesity and the risk of developing breast cancer among postmenopausal women," American Journal of Epidemiology, vol. 174, no. 8, pp. 919-928, 2011.
[16] J. E. Ware Jr. and C. D. Sherbourne, “The MOS 36-item shortform health survey (SF-36). I. Conceptual framework and item selection," Medical Care, vol. 30, no. 6, pp. 473-483, 1992.

[17] J. A. Freeman, J. C. Hobart, D. W. Langdon, and A. J. Thompson, "Clinical appropriateness: a key factor in outcome measure selection: the 36 item short form health survey in multiple sclerosis," Journal of Neurology Neurosurgery and Psychiatry, vol. 68, no. 2, pp. 150-156, 2000.

[18] S. Katz, A. B. Ford, R. W. Moskowitz, B. A. Jackson, and M. W. Jaffe, "Studies of illness in the aged," The Journal of the American Medical Association, vol. 185, pp. 914-919, 1963.

[19] J. E. Manson, P. Greenland, A. Z. LaCroix et al., "Walking compared with vigorous exercise for the prevention of cardiovascular events in women," The New England Journal of Medicine, vol. 347, no. 10, pp. 716-725, 2002.

[20] G. A. Greendale, B. A. Reboussin, P. Hogan et al., "Symptom relief and side effects of postmenopausal hormones: results from the postmenopausal estrogen/progestin interventions trial," Obstetrics and Gynecology, vol. 92, no. 6, pp. 982-988, 1998.

[21] J. A. Cauley, M. E. Danielson, R. Boudreau et al., "Serum 25hydroxyvitamin $\mathrm{D}$ and clinical fracture risk in a multiethnic cohort of women: the Women's Health initiative (WHI)," Journal of Bone and Mineral Research, vol. 26, no. 10, pp. 23782388, 2011.

[22] L. S. Radloff, "The CES-D scale: a self-report depression scale for research in the general population," Applied Psychological Measurement, vol. 1, no. 3, pp. 385-401, 1977.

[23] R. D. Langer, E. White, C. E. Lewis, J. M. Kotchen, S. L. Hendrix, and M. Trevisan, “The Women's Health Initiative Observational study: baseline characteristics of participants and reliability of baseline measures," Annals of Epidemiology, vol. 13, no. 9, pp. S107-S121, 2003.

[24] CDC/NCHS, National Health Interview Study, 2012, Sample Adult Core Component.

[25] M. Emre and C. de Decker, "Effects of cigarette smoking on motor functions in patients with multiple sclerosis," Archives of Neurology, vol. 49, no. 12, pp. 1243-1247, 1992.

[26] H. Q. Nguyen, J. R. Herting, R. Kohen et al., "Recreational physical activity in postmenopausal women is stable over 8 years of follow-up," Journal of Physical Activity \& Health, vol. 10, no. 5, pp. 565-568, 2013.

[27] A. Shirani and H. Tremlett, "The effect of smoking on the symptoms and progression of multiple sclerosis: a review," Journal of Inflammation Research, vol. 3, no. 1, pp. 115-126, 2010.

[28] K. E. Hill, L. V. Zollinger, H. E. Watt, N. G. Carlson, and J. W. Rose, "Inducible nitric oxide synthase in chronic active multiple sclerosis plaques: distribution, cellular expression and association with myelin damage," Journal of Neuroimmunology, vol. 151, no. 1-2, pp. 171-179, 2004.

[29] J. Salzer, G. Hallmans, M. Nystrom, H. Stenlund, G. Wadell, and P. Sundstrom, "Smoking as a risk factor for multiple sclerosis," Multiple Sclerosis Journal, vol. 19, no. 8, pp. 1022-1027, 2013.

[30] P. Sundström and L. Nyström, "Smoking worsens the prognosis in multiple sclerosis," Multiple Sclerosis, vol. 14, no. 8, pp. 10311035, 2008.

[31] R. A. Marrie, G. Cutter, T. Tyry, D. Campagnolo, and T. Vollmer, "Validation of the NARCOMS registry: diagnosis," Multiple Sclerosis, vol. 13, no. 6, pp. 770-775, 2007. 


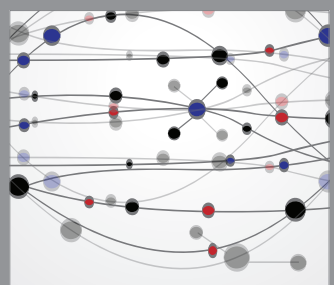

The Scientific World Journal
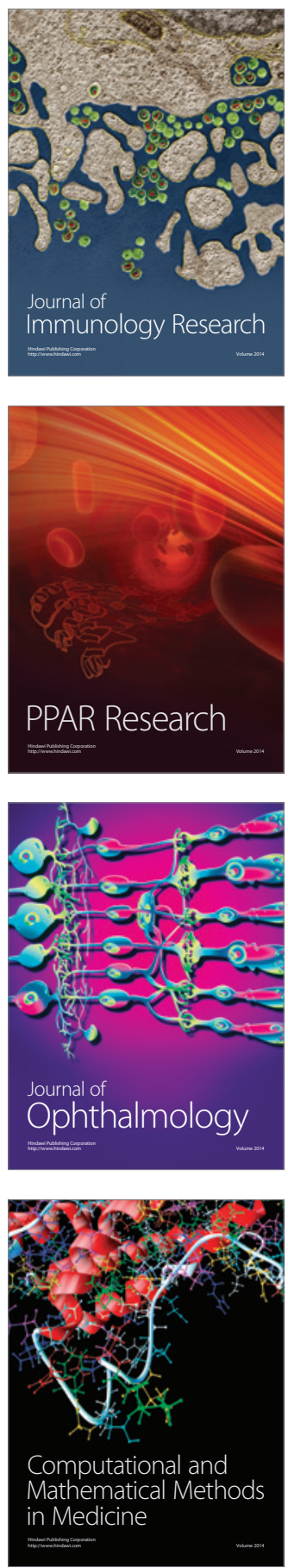

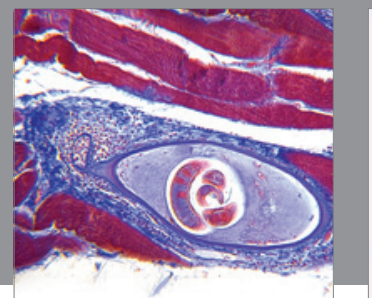

Gastroenterology

Research and Practice
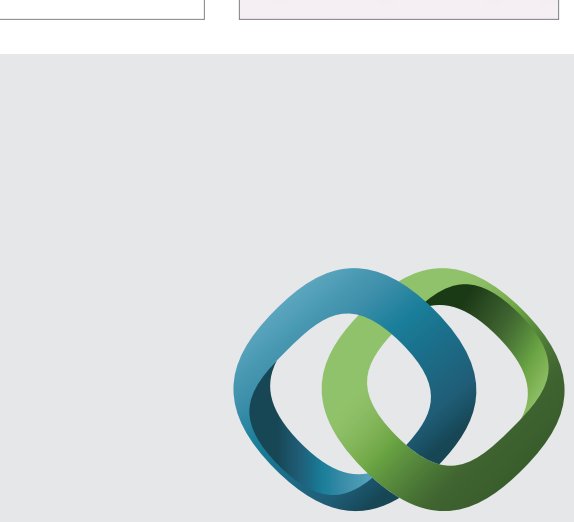

\section{Hindawi}

Submit your manuscripts at

http://www.hindawi.com
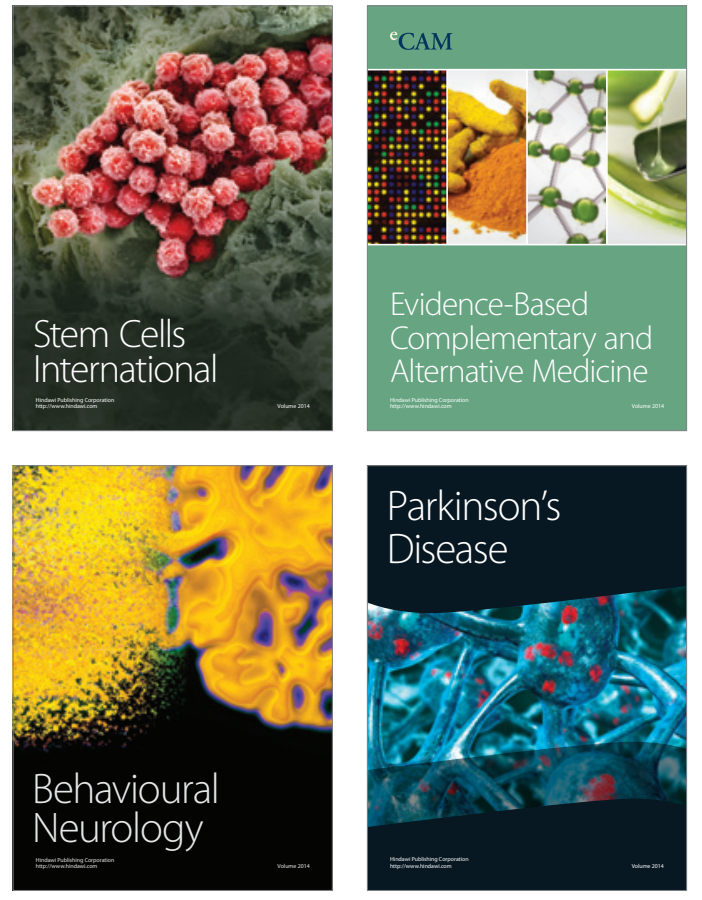
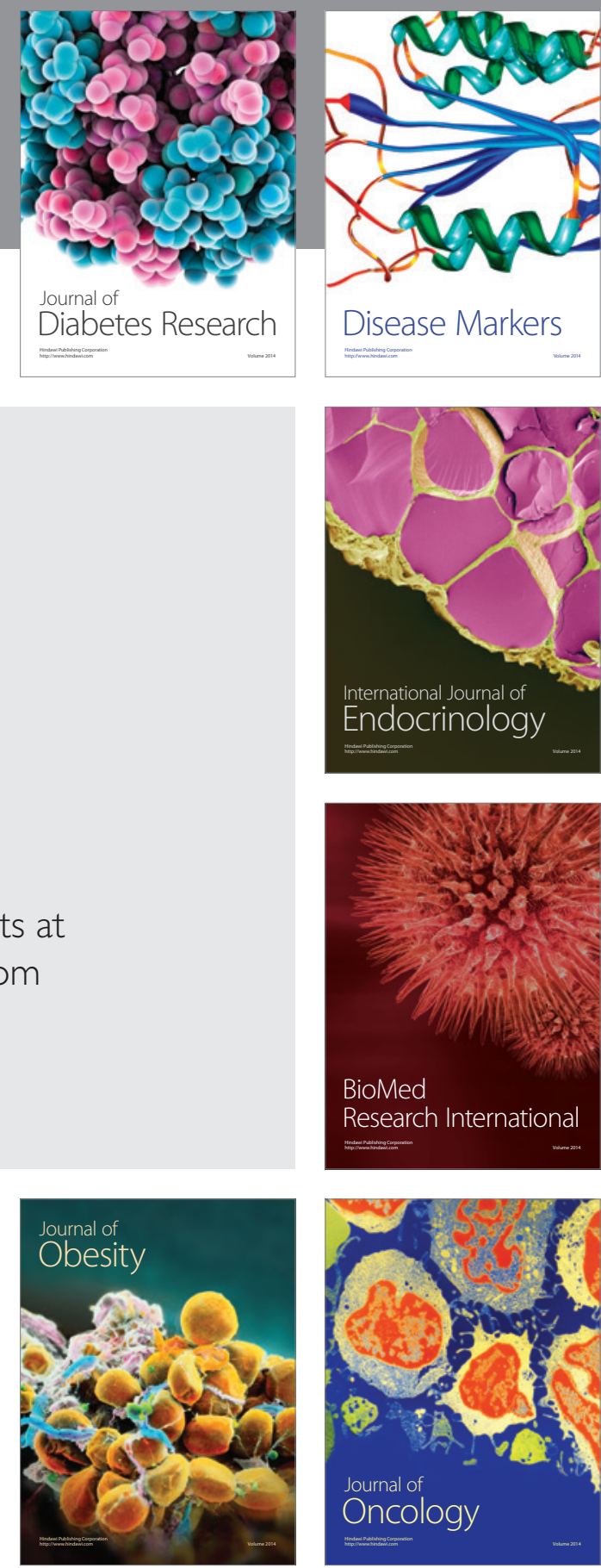

Disease Markers
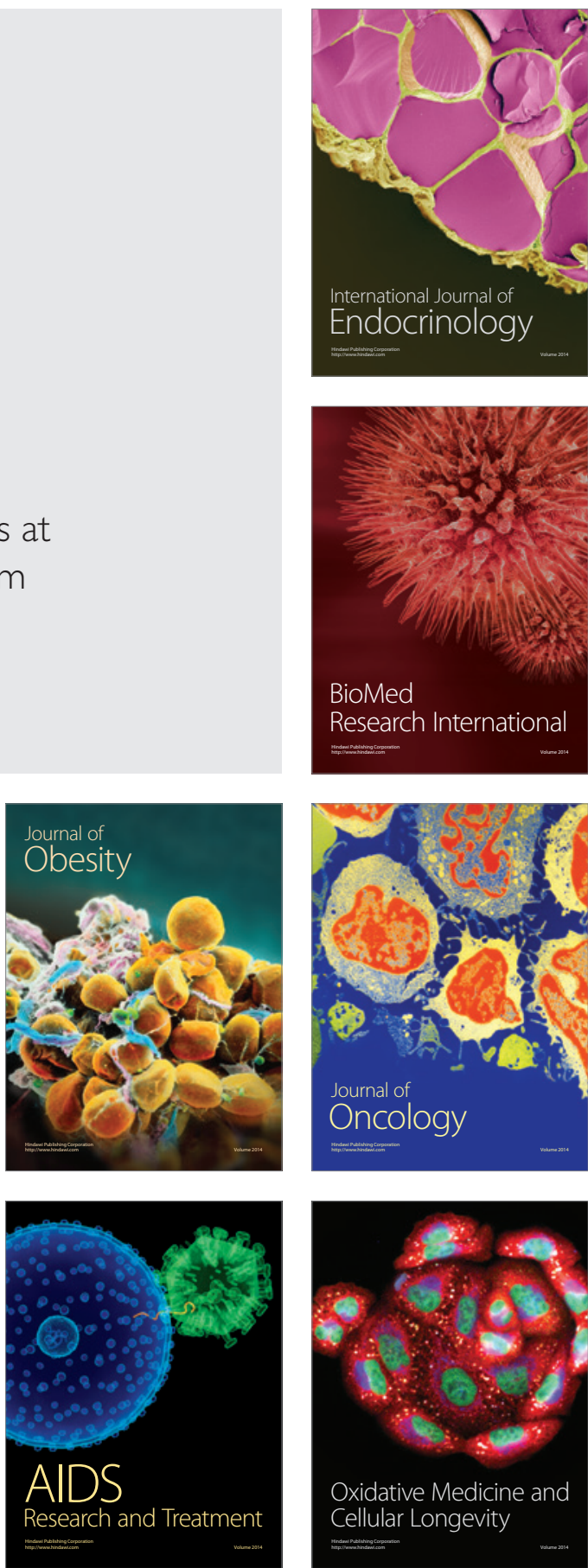